\title{
Prevalentie van urolithiasis en andere urinaire afwijkingen bij honden met een congenitale extrahepatische portosystemische shunt
}

\author{
Prevalence of urolithiasis and other urinary abnormalities in dogs with a \\ congenital extrahepatic portosystemic shunt
}

${ }^{1}$ T. Van Riet, ${ }^{1}$ N. Devriendt, ${ }^{1}$ G. Serrano, ${ }^{2}$ E. Stock, ${ }^{1}$ D. Paepe, ${ }^{1}$ H. de Rooster

${ }^{1}$ Vakgroep Kleine Huisdieren

${ }^{2}$ Vakgroep Medische Beeldvorming van de Huisdieren en Orthopedie van de Kleine Huisdieren Faculteit Diergeneeskunde, Salisburylaan 133, B-9820 Merelbeke

nausikaa.devriendt@ugent.be

\section{AMENVATTING}

Honden met een portosystemische shunt (PSS) vertonen vaak urinaire afwijkingen. In deze retrospectieve studie werd de prevalentie van urolithiasis en andere urinewegklachten secundair aan extrahepatische (EH)PSS nagegaan vanaf het optreden van de eerste klachten tot en met de dag van de chirurgische correctie van de EHPSS. Enerzijds werd $67 \%$ van de onderzochte honden aangeboden met urinewegklachten die rechtstreeks $(39 \%)$ of waarschijnlijk $(28 \%)$ verband hielden met EHPSS. Zo werden sommige honden chirurgisch behandeld voor urolithiasis, waarna via kwantitatieve steenanalyse ammoniumbiuraat-urolieten vastgesteld werden, wat de aanwezigheid van een onderliggende PSS deed vermoeden. Anderzijds bleek $\mathbf{7 7 \%}$ van de honden zonder urinewegklachten toch abnormaliteiten te vertonen op medische beeldvorming en/ of het urinewegonderzoek. In totaal werden er bij $\mathbf{7 0 , 4 \%}$ van de honden urolieten vastgesteld. In dit onderzoek wordt het belang aangetoond van het uitvoeren van een volledig urineonderzoek aangevuld met medische beeldvorming van het urinaire stelsel bij alle honden met EHPSS. Daarnaast wordt de meerwaarde van een kwantitatieve steenanalyse beklemtoond, opdat bij aanwezigheid van ammoniumbiuraat aan een mogelijke PSS wordt gedacht.

\section{ABSTRACT}

Dogs with a portosystemic shunt (PSS) often have urinary abnormalities. In this retrospective study, the prevalence of urolithiasis and other urinary abnormalities secondary to extrahepatic (EH)PSS was determined from the onset of the clinical signs until the day of surgical correction of the PSS. About $67 \%$ of all dogs were presented with urinary complaints that were directly $(39 \%)$ or probably $(28 \%)$ related to the EHPSS. Some dogs had surgery for urolithiasis and subsequent quantitative stone analysis revealed ammonium biurate uroliths, suggesting the presence of an underlying PSS. Additionally, $77 \%$ of the dogs that did not have any urinary complaints appeared to have urinary abnormalities based on medical imaging and/or urinalysis. Overall, $70.4 \%$ of the dogs had urolithiasis. In this study, the importance of performing a complete urinalysis, supplemented with medical imaging of the urinary system in all dogs with an EHPSS is demonstrated. In addition, the importance of quantitative analysis of uroliths is stressed, as the presence of ammonium biurate may be suggestive of a PSS. 


\section{INLEIDING}

De lever is het orgaan met een van de meest complexe vascularisatiepatronen in het lichaam. Het ontvangt bloed via twee verschillende wegen, namelijk via de vena portae en via de arteria hepatica (Markowitz et al., 1949). Een goede bloedtoevoer naar de lever is van belang voor het onderhoud van de leverfunctie en -massa, waarbij zowel de hoeveelheid bloed als de kwaliteit van het bloed een belangrijke rol speelt. De vena portae is verantwoordelijk voor een groot deel van de functie en massa van de lever en voert bloed aan dat afkomstig is van de pancreas, milt en het gastro-intestinale stelsel. Via de vena portae worden verschillende nutriënten, toxines, bacteriën en hepatotrofe factoren, bijvoorbeeld "insulinelike growth factor", glucagon, insuline en "hepatocyt growth factor", naar de lever aangevoerd (van den Ingh et al., 1995).

Bij een portosystemische shunt (PSS) komt het bloed afkomstig van het gastro-intestinale stelsel, milt en/of pancreas via een abnormaal bloedvat, onmiddellijk terecht in de systemische circulatie zonder eerst door de leversinusoïden te passeren. Hierdoor kan de lever zijn normale functie niet uitvoeren en wordt het bloed niet ontgift. Ook hepatotrofe factoren afkomstig van de pancreas en de dunne darm komen niet tot in de lever, waardoor de lever niet in staat is de normale grootte te bereiken of zal atrofiëren, met als gevolg dat de leverfunctie ondermaats is (van den Ingh et al., 1995). Portosystemische shunts kunnen onderverdeeld worden in intra- $(\mathrm{IH})$ en extrahepatische (EH)PSSs en kunnen congenitaal of verworven zijn. Naargelang hun uitmonding kunnen EHPSSs onderverdeeld worden in portocavale, portofrenische en portoazygos-shunts (Nelson en Nelson, 2011).

De klinische tekenen bij honden met een PSS zijn variabel. Zo kunnen er neurologische, gastrointestinale, urinaire en aspecifieke klachten voorkomen (Howe en Boothe, 2002; Winkler et al., 2003; Paepe et al., 2007; Berent en Tobias, 2009). Honden met een PSS zijn vatbaar voor de ontwikkeling van ammoniumbiuraat-kristallurie en urolithiasis (Winkler et al., 2003; Mehl et al., 2005; Berent en Weisse, 2007; Berent en Tobias, 2009). Door de verminderde leverfunctie gaan de ureumcyclus en urinezuurcyclus minder door met als gevolg dat er een overmaat aan ammoniak en uraat uitgescheiden wordt door de nieren in de urine (Dimski, 1994). De daaruit volgende ammoniumuraat sediment- en steenvorming leidt vaak tot lage-urinewegsymptomen, zoals pollakisurie, hematurie, dysurie of strangurie. Ook polyurie en polydipsie kunnen voorkomen (Berent en Weisse, 2007; Berent en Tobias, 2009).

In de literatuur over EHPSSs worden urinewegproblemen weliswaar vaak vernoemd, maar zelden afzonderlijk bestudeerd. In dit artikel wordt de prevalentie van urolithiasis en andere secundaire urinaire klachten, zoals sediment, urineweginfecties en abnor- maliteiten van de urinewegen op medische beeldvorming en urineonderzoek, nagegaan bij een populatie honden met een congenitale EHPSS vooraleer hun shunt chirurgisch vernauwd werd.

\section{MATERIAAL EN METHODEN}

Er werd een retrospectieve studie uitgevoerd bij honden die een chirurgische correctie ondergingen van een congenitale EHPSS in de Kliniek Kleine Huisdieren, Faculteit Diergeneeskunde, Universiteit Gent, tussen 1 juni 2012 en 31 mei 2018. Per patiënt werd de periode van het moment waarop de eerste klinische klachten optraden die in verband gebracht werden met de EHPSS, tot en met de dag van chirurgische correctie in beschouwing genomen. Verschillende patiënten hadden meerdere controlebezoeken vooraleer er tot chirurgie werd overgegaan; daarvan werden alle resultaten in deze studie opgenomen.

De informatie werd enerzijds bekomen via het kliniekprogramma en anderzijds via een door de eigenaar ingevulde standaardvragenlijst die speciaal voor honden met een EHPSS werd ontworpen en vanaf juni 2012 voor bijna elke hond met een EHPSS werd vervolledigd.

Eerst en vooral werd in het kliniekprogramma een selectie gemaakt van alle honden die in de opgegeven periode werden aangeboden voor chirurgische correctie van een EHPSS. Van deze honden werden volgende gegevens in een Excel-bestand opgenomen: naam, ras, geslacht, leeftijd bij de eerste consultatie in de kliniek, gewicht en voedingstoestand (body condition score (BCS)). Hondenrassen waarvan het normale lichaamsgewicht $<10 \mathrm{~kg}$ was, werden gedefinieerd als 'klein ras', en hondenrassen waarvan het normale lichaamsgewicht tussen 10-25 kg lag, werden gedefinieerd als 'middelgroot ras'.

De anamnese van de eerste consultatie op de kliniek en de aanwezige verslagen van de doorsturende dierenarts werden doorgenomen. Er werd aandacht besteed of en met welke urinewegklacht(en) de hond zich aanbood. Vervolgens werden de door de eigenaars ingevulde vragenlijsten grondig bestudeerd. In deze vragenlijsten werd er specifiek gevraagd naar de frequentie van het voorkomen van verschillende mogelijke urineweg-, gastro-intestinale en neurologische symptomen. De hoofdklacht en overige klachten werden genoteerd en er werd een onderscheid gemaakt tussen verschillende categorieën: urinewegklachten, gastro-intestinale klachten, neurologische klachten en andere. Er werd gekeken naar de leeftijd waarop de eerste klinische symptomen aanwezig waren; dit werd ingedeeld in verschillende leeftijdscategorieën. Wanneer er urinewegklachten aanwezig waren, werden deze verder getypeerd en onderverdeeld in lage-urinewegklachten, bijvoorbeeld hematurie en strangurie, en niet-specifieke klachten die het gevolg kunnen zijn van een onvolledig getrainde pup, bijvoorbeeld peri- 
urie en pollakisurie. Er werd nagegaan of er in het verleden urolithiasis werd gediagnosticeerd. De samenstelling van de urolieten werd genoteerd voor zover die bekend was.

Vervolgens werd ook nagegaan of er een urineonderzoek werd uitgevoerd. Indien er op verschillende tijdstippen een urineonderzoek werd uitgevoerd, werden al deze data in de studie opgenomen. Tijdens het urineonderzoek werd gekeken naar de aanwezigheid van kristallen en indien er kristallurie was, om welke kristallen het ging. Er werd nagegaan of er andere urinaire abnormaliteiten aanwezig waren, zoals microscopische hematurie en pyurie (respectievelijk gestegen rode bloedcellen en witte bloedcellen in urine), gestegen eiwit/creatinine-ratio $(>0,5)$, afwijkingen in $\mathrm{pH}$ en of honden hypo- of isostenurische urine hadden. Indien er een bacteriologisch onderzoek werd uitgevoerd, werd nagegaan of dit negatief of positief was. Voor positieve bacteriële urineculturen werd de gekweekte bacterie genoteerd.

Er werd ook gekeken welke medische beeldvormingstechnieken werden gebruikt bij de verdere "work-up" van de urinewegklachten, het diagnosticeren van EHPSSs en wat de bevindingen waren. Er werd nagegaan of er sediment en/of urolieten aanwezig waren in het urinaire stelsel. De lokalisatie van urolieten werd weergegeven. Indien er bij een hond cystotomie werd uitgevoerd, werd er een onderscheid gemaakt tussen cystotomie voor en tijdens de chirurgische correctie van de EHPSS. Het aantal verwijderde urolieten, hun grootte, aspect en de kwantitatieve samenstelling werden opgenomen indien deze gegevens beschikbaar waren.

Data van honden die enkel medicamenteus werden behandeld voor een EHPSS, werden niet opgenomen in dit onderzoek.

\section{RESULTATEN}

\section{Signalement}

In totaal werden 54 honden in de studie ingesloten. Alhoewel de eerste klinische symptomen bij 72,2\% van de honden vóór de leeftijd van één jaar optraden, werd $51,9 \%$ pas in de kliniek angeboden wanneer ze ouder waren dan één jaar (Figuur 1). De gemiddelde leeftijd bij het aanbieden in de kliniek bedroeg 21,7 \pm 20,9 maanden. Er waren evenveel mannelijke $(77,8 \%$ intact, $22,2 \%$ gecastreerd) als vrouwelijke $(55,6 \%$ intact, $44,4 \%$ gecastreerd) honden. Het overgrote gedeelte $(87,0 \%)$ behoorde tot een klein ras, de overige $13,0 \%$ tot een middelgroot ras. De meest voorkomende rassen waren maltezer $(n=10,18,5 \%)$ en yorkshire terriër $(n=9,16,7 \%)$. Het gemiddelde gewicht bij de eerste aanbieding op de kliniek was 4,5 $\pm 3,1 \mathrm{~kg}$, waarbij twee derden van de patiënten een te lage BCS had (mediaan 3 op 9, range 2-7).

\section{Urinewegklachten}

Bij 21 (elf honden waren mannelijk en tien vrouwelijk) van de 54 honden $(38,9 \%)$ werden door de eigenaar urinewegklachten gemeld die (zeer waarschijnlijk) verband hielden met de aanwezigheid van een EHPSS. Bij negen van hen werd door de eigenaar een urinewegprobleem als hoofdklacht opgegeven: bij zes als enige hoofdklacht, bij twee als een combinatie van een urinewegprobleem en gastro-intestinaal probleem en bij één hond als een combinatie van urineweg- en neurologische afwijkingen. Bij de overige twaalf honden waren de neurologische en/of gastro-intestinale klachten overwegend aanwezig. De specifieke EHPSS-gerelateerde urinaire klachten bij

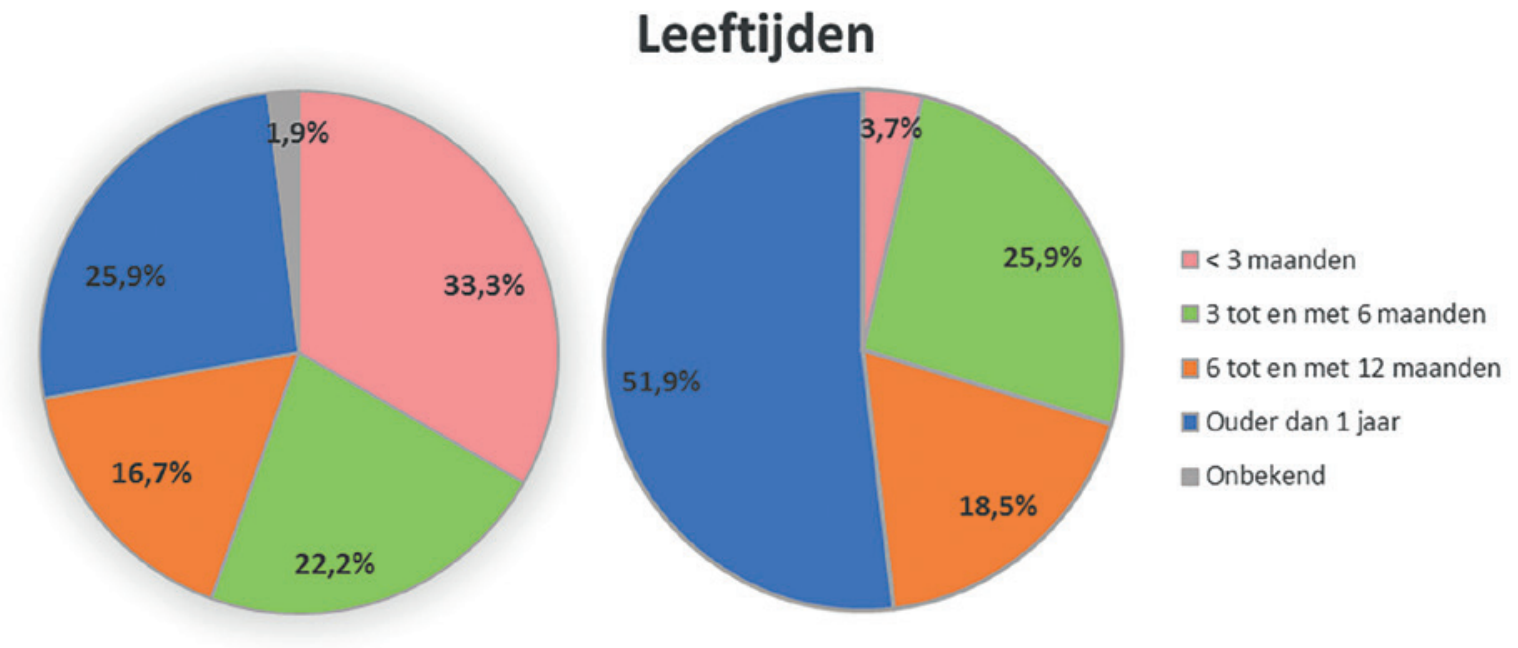

Figuur 1. Leeftijd van de honden met een congenitale extrahepatische portosystemische shunt bij de ontwikkeling van de eerste klinische klachten (links) en bij het aanbieden in de kliniek (rechts). 
de 21 honden waren: hematurie $(n=16,76,2 \%)$, strangurie $(n=7,33,3 \%)$ en dysurie (eveneens $n=7,33,3 \%)$. In een derde van de gevallen met specifieke urinaire klachten traden al problemen op vóór de hond drie maanden oud was.

Verder werden er bij twintig honden $(37,0 \%)$ enkel niet-EHPSS-specifieke urinewegklachten, zoals pollakisurie en periurie, gerapporteerd door de eigenaar. Slechts bij 15 van hen (acht mannelijke, zeven vrouwelijke) bracht verdere diagnostiek (een) abnormaliteit(en) van de urine of het urinaire stelsel aan het licht: bij 13/15 was er sprake van urolithiasis, bij 8/15 was er sediment in de blaas en bij 3/15 was er een urineweginfectie.

Bij de overblijvende 13 honden $(24,1 \%)$ waren er volgens de eigenaars geen preoperatieve urinaire klachten aanwezig, alhoewel er bij tien van deze honden (vijf mannelijke, vijf vrouwelijke) bij verder onderzoek afwijkingen in het urineonderzoek en/of het urinaire stelsel werden vastgesteld: bij 9/10 was er sprake van urolithiasis en bij 5/10 was er sediment in de blaas aanwezig.

\section{Urineonderzoek}

Bij 41 van de 54 honden werd een urineonderzoek uitgevoerd waarvan slechts bij dertig honden het resultaat van deze analyse beschikbaar was voor retrospectief onderzoek. Volgende afwijkingen werden vastgesteld: microscopische hematurie $(n=14)$, gestegen eiwit/creatinine-ratio $(n=14)$, alkalische $\mathrm{pH}$ $(n=12)$, pyurie $(n=11)$. In totaal hadden 11 honden hypostenurische en 16 isostenurische urine. In totaal hadden 2/14 honden met een gestegen eiwit/creatinine-ratio een inactief sediment.

In totaal werd de urine bij 31 honden minstens eenmaal gecontroleerd op kristallurie door microscopisch onderzoek. Zestien (zeven mannelijke, negen vrouwelijke) van de $31(51,6 \%)$ waren positief. De meest voorkomende kristaltypes waren struviet $(n=5)$, ammoniumbiuraat $(n=3)$ of een combinatie van beide $(n=4)$. Overige types waren: calciumoxalaat $(n=2)$, de combinatie calciumoxalaat en ammoniumbiuraat $(n=1)$ en het resultaat van één uroliet was niet bekend. Bij sommige honden werden verschillende kristaltypes gezien gespreid over de tijd.

Een bacteriologisch onderzoek van een urinestaal werd aangevraagd bij 36 van de 54 honden met een EHPSS (66,6\%); het resultaat was beschikbaar voor 35 honden. Bij vijf van de 35 honden (14,3\%, alle vrouwelijk) was in de periode van de eerste consultatie bij de (eigen) dierenarts tot en met de correctie van een EHPSS, minstens één cultuur positief; drie van deze honden hadden urolithiasis. Er werden verschillende soorten bacteriën geïdentificeerd (Acinetobacter Baumanii complex, Escherichia coli, E. coli in combinatie met Klebsiella pneumoniae, Enterococcus fecalis en Proteus mirabilis gevolgd door E.coli).

\section{Medische beeldvorming}

Hoewel alle 54 honden door middel van één of meerdere beeldvormingsmodaliteiten gescreend werden, lag de focus van dit beeldvormingsonderzoek meestal op het bevestigen van de aanwezigheid van een congenitale EHPSS. In totaal werd er een abdominale echografie uitgevoerd bij 52 honden (96,3\%), een abdominale CT bij 16 honden (29,6\%), een transsplenische portale scintigrafie bij 12 honden $(22,2 \%)$ en radiografieën van het abdomen bij acht honden $(14,8 \%)$, waarbij slechts bij twee een retrograad contrast-cystogram werd gemaakt. Over de volledige studieperiode werden bij 38 honden $(70,4 \%)$ urolieten vastgesteld. Via één of meerdere beeldvormingstechnieken werd bij 18 van de 54 honden met een congenitale EHPSS (33,3\%) bilaterale renomegalie vastgesteld. In totaal werden bij 38 van de 54 honden $(70,4 \%)$ urolieten in de blaas aangetroffen, waar-

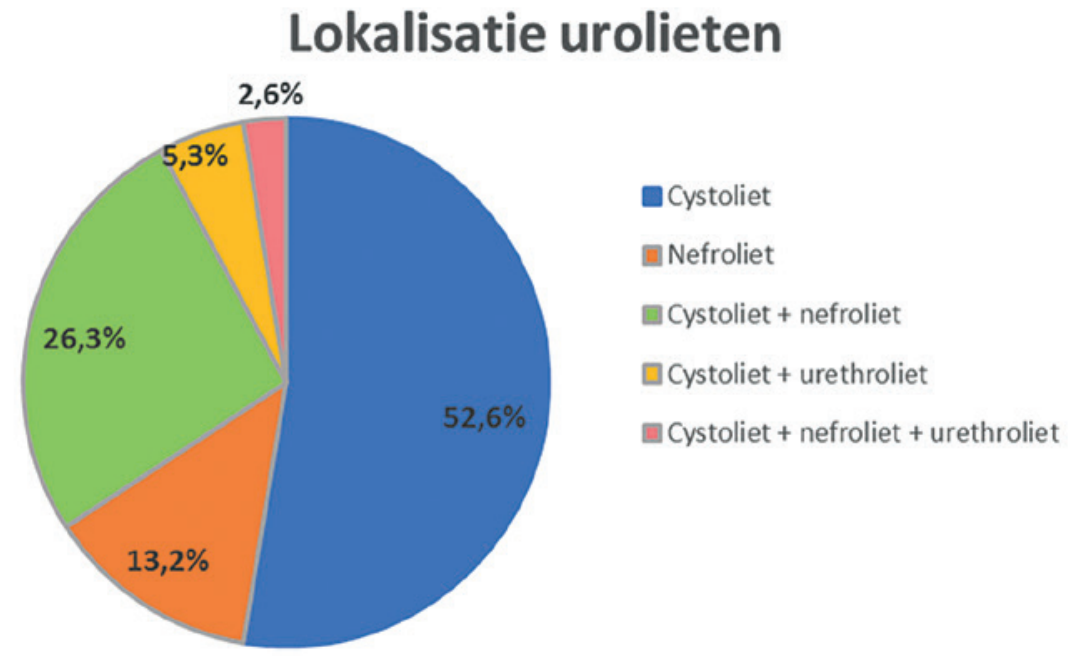

Figuur 2. Lokalisatie van urolieten bij 38 van de onderzochte honden met congenitale extrahepatische portosystemische shunt. 
van er 15 ook sediment in de blaas hadden. Slechts bij drie van de 54 honden $(5,5 \%)$ werd er enkel sediment in de blaas waargenomen zonder de aanwezigheid van een uroliet. Bij 13 honden (24,1\%) werd er sediment noch urolieten waargenomen in de blaas.

De locaties van de desbetreffende urolieten wordt weergegeven in Figuur 2. Bij 32 van deze 38 honden waren urolieten aanwezig op de dag dat de honden naar de kliniek kwamen voor de chirurgische correctie van een EHPSS. Bij drie van de 38 honden werden urethrolieten vastgesteld: één reu werd in spoed aangeboden met urethraobstructie en de andere twee reuen hadden niet-obstructieve urethrolieten.

\section{Chirurgische behandeling van urolithiasis}

Bij 33 van de 38 honden waarbij urolieten werden vastgesteld, waren cystolieten aanwezig. Bij 54,5\% $(n=18)$ van deze laatste honden werd cystotomie uitgevoerd waarvan bij $16,7 \%(\mathrm{n}=3)$ vóór de chirurgische correctie van de shunt, bij 72,2\% $(n=13)$ tijdens de chirurgische correctie van de EHPSS (waaronder bij de reu met urethraobstructie) en bij twee honden $(11,1 \%)$ werd zowel vóór als tijdens de chirurgische correctie van de shunt cystotomie uitgevoerd. Van de overige honden met cystolieten waarbij geen cystotomie werd uitgevoerd $(n=15)$, werden bij zeven honden (drie mannelijke en vier vrouwelijke) enkel cystolieten gediagnosticeerd door de eigen dierenarts, die vermoedelijk met de urine geëvacueerd werden ofwel eigenlijk toch eerder enkel sediment waren. Bij de overige honden (zes mannelijke, twee vrouwelijke) waren de cystolieten die bevestigd werden in de kliniek, echter klein en vormden ze dus geen probleem. In totaal werd bij vijf honden cystotomie uitgevoerd vooraleer de diagnose van een PSS werd gesteld; drie van deze honden ondergingen opnieuw cystotomie tijdens de chirurgische ingreep voor een EHPSS.

\section{Steenanalyse}

Bij 11 van de 18 honden waarbij één of herhaalde cystotomieën werden uitgevoerd, werd de kwantitatieve samenstelling van de urolieten bepaald. Alle cystolieten bevatten ammoniumbiuraat. Bij zeven honden waren ze opgebouwd uit 100\% ammoniumbiuraat; ze waren groen van kleur en glad van oppervlak. In de overige vier gevallen was een combinatie van ammoniumbiuraat en struviet aanwezig, waarbij het oppervlak van de uroliet een meer onregelmatig aspect vertoonde.

\section{DISCUSSIE}

Bij 75\% van de honden in deze studie met een congenitale EHPSS meldden de eigenaars lage-urinewegklachten, hoewel die niet steeds met zekerheid verband hielden met de aanwezigheid van een PSS. De voornaamste urinewegklachten die voorkomen bij honden met een EHPSS zijn hematurie, strangurie, pollakisurie en/of urethra(sub)obstructie ten gevolge van de vorming van urolieten (Mehl et al., 2005; Berent en Weisse, 2007; Worley en Holt, 2008; Kraun et al., 2014; Caporali et al., 2015). Het percentage van urinewegklachten in eerdere studies ligt tussen de 2147\% (Mehl et al., 2005; Worley en Holt, 2008; Kraun et al., 2014; Caporali et al., 2015). Helaas worden de urinaire klachten in de literatuur meestal weinig gespecificeerd, waardoor niet duidelijk is welke klachten opgenomen werden en over welke tijdspanne deze bekeken werden. Om die reden werd in de huidige studie, in tegenstelling tot eerdere studies (Kraun et al., 2014; Caporali et al., 2015), een onderscheid gemaakt tussen specifieke urinewegklachten en niet-specifieke urinewegklachten (die verband kunnen houden met onzindelijkheid bij pups) en werd de voorgeschiedenis opgenomen.

Ammoniumbiuraat cystolieten zijn typisch glad indien ze voor $100 \%$ uit ammoniumbiuraat bestaan (Bartges et al., 1999). Daardoor wordt de blaaswand weinig geprikkeld en kan hun aanwezigheid bijgevolg asymptomatisch zijn. Ook nefrolieten kunnen asymptomatisch zijn, hoewel ze in sommige gevallen milde hematurie veroorzaken (Bartges et al., 1999). De urinaire eiwit/creatinine-ratio was in de voorliggende studie gestegen bij nagenoeg de helft van de geteste honden. De overgrote meerderheid van deze patiënten had actief sediment, wat wijst op de aanwezigheid van postrenale proteïnurie. Het is echter mogelijk dat er bij EHPSS milde renale proteïnurie aanwezig is, secundair aan glomerulaire laesies (Tisdall et al., 1996). Bij 10/54 (18,5\%) van de patiënten werden via urineonderzoek of medische beeldvorming afwijkingen vastgesteld, zoals sediment in de blaas, urolithiasis en urineweginfectie, terwijl er volgens de eigenaars geen klachten waren. Ook in een eerdere studie werden bij opvallend meer honden afwijkingen vastgesteld op verder onderzoek dan dat de eigenaars klinische symptomen hadden vastgesteld (Caporali et al., 2015). Anderzijds waren urinewegproblemen bij 15/54 (27,8\%) honden met een congenitale EHPSS de enige reden of hoofdreden waarvoor de hond aanvankelijk aangeboden werd voor onderzoek.

Bij de bestudeerde populatie werd helaas niet bij alle honden gecontroleerd en/of genoteerd of er kristallurie aanwezig was. In de onderzochte urinestalen werden bij iets meer dan de helft van de gevallen kristallen opgemerkt, voornamelijk struviet- en/of ammoniumbiuraatkristallen. In eerdere studies werd kristallurie bij 34-72\% van de honden met een EHPSS vermeld, waarvan $42-52 \%$ ammoniumbiuraatkristallurie (Mehl et al., 2005; Kraun et al.,2014; Caporali et al., 2015). Een zo recent mogelijk urinestaal geeft de meest betrouwbare resultaten (Albasan et al., 2003), wat een verklaring zou kunnen zijn voor de ver uiteenlopende percentages. De urineonderzoeken werden deels in het laboratorium van de kliniek en deels in een extern laboratorium uitgevoerd, wat invloed kan hebben op de betrouwbaarheid van de analyse, 
voornamelijk voor wat betreft de aanwezigheid van kristallurie en pH-bepalingen. Het type kristal dat gevonden wordt, is bovendien niet noodzakelijk representatief voor de component(en) waaruit de uroliet(en) bestaan en urolieten kunnen ook voorkomen zonder dat er kristallurie aanwezig is (Bartges et al., 1999). Daarom is het aan te raden zowel een urineonderzoek als medische beeldvorming uit te voeren om afwijkingen in het urinewegstelsel op te sporen. Hoewel metabole urolithiasis minder vaak gepaard gaat met bacteriële cystitis dan andere vormen van urolithiasis door hun gladde oppervlakte, kunnen secundaire urineweginfecties optreden (Osborne et al., 1986, Bartges et al., 1999; Caporali et al., 2015).

Bij de honden in de huidige studie werden bij $70,4 \%$ ooit urolieten gevonden in de periode tot en met het aanbieden in de kliniek voor chirurgische correctie. In een vorige studie werd het mannelijke geslacht als risicofactor geïdentificeerd (Caporali et al., 2015), maar in de huidige studie waren reuen niet gepredisponeerd. In een onderzoek naar de echografische bevindingen bij patiënten met vasculaire leveraandoeningen werd bij honden met een congenitale EHPSS een gelijkaardig percentage urolieten vastgesteld (D'Anjou et al., 2004) terwijl in enkele andere studies opvallend minder (30-36\%) urolieten gerapporteerd werden (Hurn en Edwards, 2003; Winkler et al., 2003; Caporali et al., 2015). Een mogelijke reden waarom het aantal in de literatuur beduidend lager ligt, is dat in de huidige studie ook de voorgeschiedenis van urolithiasis opgenomen werd. Indien enkel de aanwezigheid van urolieten in beschouwing genomen wordt op het moment dat de dieren aangeboden werden op de Faculteit Diergeneeskunde, dan daalde het percentage tot $59,3 \%$. Daarnaast werd iets meer dan de helft van de honden met een congenitale EHPSS voor het eerst bij een dierenarts aangeboden toen ze ouder waren dan één jaar. Patiënten die ouder zijn dan 10,8 maanden, hebben een verhoogd risico op urolithiasis (Caporali et al., 2015). Een andere reden, waardoor de percentages sterk kunnen verschillen, is een systematische onderschatting van urolithiasis bij de initiële diagnose van een EHPSS. Ammoniumbiuraat-urolieten worden tijdens radiografisch onderzoek gemakkelijk gemist en kunnen niet gediagnostiseerd worden met scintigrafie (Lamb, 1998). Bij de vakgroep Kleine Huisdieren van de Faculteit Diergeneeskunde wordt nagenoeg altijd een abdominale echografie uitgevoerd bij shunt-verdachte honden. Echografie is zeer gevoelig om urolieten te detecteren, zelfs wanneer ze radiolucent en/of zeer klein zijn (Lamb, 1998; D'Anjou et al., 2004). Een bijkomend voordeel van abdominale echografie is dat niet alleen de PSS zelf in beeld kan gebracht worden, maar ook de rest van het abdomen geëvalueerd kan worden. Zelfs indien de PSS zelf niet gezien wordt, dan geeft een combinatie van de aanwezigheid van microhepatie, renomegalie en urolieten een sterk vermoeden aan dat er een PSS aanwezig is. Renomegalie wordt vaak vastgesteld op echografie bij honden met een EHPSS (d'Anjou et al.,
2004) en ook in de huidige studie werd renomegalie waargenomen bij meer dan een derde van de honden.

In de onderzochte populatie werden de meeste urolieten gelokaliseerd in de blaas en/of nieren; slechts een klein percentage van de onderzochte honden werd aangeboden met urethrolieten zoals eerder beschreven werd (Kraun et al., 2014, Caporali et al., 2015). Anderzijds is het belangrijk op te merken dat sommige honden cystotomie ondergingen en pas later gediagnosticeerd werden met een EHPSS (Mehl et al., 2005; Worley en Holt, 2008; Kraun et al., 2014). Urethraobstructie komt vaker voor bij mannelijke dieren dan vrouwelijke dieren omdat de urethra van een vrouwelijke hond korter en breder is, waardoor kleine urolieten zonder obstructie kunnen passeren (Evans en de Lahunta, 2013). Bij 54,5\% van de honden, waarbij cystolieten werden vastgesteld, werden één of meerdere cystotomieën uitgevoerd. De meerderheid daarvan onderging tijdens de chirurgische correctie van de EHPSS (opnieuw) blaaschirurgie. Het is zo dat 9,3\% van de honden eerst cystotomie had ondergaan en pas later gediagnostiseerd werd met een EHPSS. Bij de cystotomieën ging het vaak om één blaassteen die te groot geacht werd voor spontane evacuatie. In eerdere studies werd cystotomie tijdens de correctie van een EHPSS beschreven bij 11-41,2\% (Mehl et al., 2005; Worley en Holt, 2008; Kraun et al., 2014). In een studie van Kraun et al. (2014) werden bij de overgrote meerderheid van de bestudeerde honden opnieuw cystolieten vastgesteld tijdens de chirurgische correctie van een EHPSS nadat de honden eerder al cystotomie hadden ondergaan. Ook in de huidige studie werden bij de helft van de honden die voor correctie van een EHPSS al cystotomie hadden ondergaan, opnieuw cystolieten verwijderd. Zolang de oorzaak van de steenvorming niet wordt aangepakt, is de kans reëel dat zich opnieuw urolieten met een ammoniumcomponent vormen (Bartges et al., 1999; Kraun et al., 2014). Het is daarom aangeraden om voorafgaand aan de EHPSS-chirurgie steeds te controleren of een (nieuwe) cystotomie nodig is.

In alle gevallen waarin de samenstelling van de cystolieten bepaald werd, was er een ammoniumbiuraatcomponent aanwezig. Ook andere studies bevestigen dat de meeste blaasstenen bij patiënten met een EHPSS voornamelijk opgebouwd zijn uit ammoniumbiuraat (Mehl et al., 2005; Kraun et al., 2014; Caporali et al., 2015), hoewel ook ammoniumbiuraat in combinatie met struviet (magnesium-ammoniumfosfaat) en zelfs zuivere struvietcystolieten aangetroffen kunnen worden (Caporali et al., 2015). Het is dus aangewezen om steeds kwantitatieve steenanalyse uit te voeren.

De voornaamste beperking van deze studie was het retrospectieve aspect, waarbij de beschikbare gegevens niet steeds volledig waren. De gestandaardiseerde vragenlijsten ingevuld door de eigenaars lieten evenwel een accuraat beeld toe van de klinische symptomen die door hen opgemerkt werden. Bij meerdere honden werd(en) echter ofwel geen volledig 
urineonderzoek en/of steenanalyse uitgevoerd ofwel niet alle resultaten gevonden, waardoor sommige bevindingen op een relatief beperkt aantal honden waren gebaseerd.

\section{CONCLUSIE}

In de huidige retrospectieve studie werd aangetoond dat $67 \%$ van de onderzochte honden met een congenitale EHPSS, urinewegklachten vertoonde. Bij sommige honden werden bovendien abnormaliteiten aan het urinaire stelsel en/of de urine vastgesteld zonder dat er klinische urinewegklachten werden opgemerkt door de eigenaar. In totaal bleek urolithiasis aanwezig te zijn bij 70,4\% van de honden. Hoewel honden met een EHPSS vaker neurologische en/of gastro-intestinale klachten vertonen, mogen de symptomatische en asymptomatische urinaire afwijkingen niet over het hoofd gezien worden. Idealiter wordt bij iedere hond met een congenitale EHPSS, een urineonderzoek gedaan en wordt het urinaire stelsel geëvalueerd op de aanwezigheid van sediment en/of urolieten. Bij elke hond met urolithiasis is het bovendien aan te raden de urolieten (indien beschikbaar) op te sturen voor een kwantitatieve analyse. Indien blijkt dat de urolieten (deels) uit ammoniumbiuraat bestaan, moet vervolgens aan een PSS worden gedacht als mogelijke oorzaak, ook indien er geen andere symptomen van een PSS aanwezig zijn.

\section{REFERENTIES}

Albasan, H., Lulich, J.P., Osborne, C.A., Lekcharoensuk, C., Ulrich, L.K., Carpenter, K.A. (2003). Effects of storage time and temperature on $\mathrm{pH}$, specific gravity, and crystal formation in urine samples from dogs and cats. Journal of American Veterinary Medical Association 222, 176-179.

Bartges, J.W., Osborne, C.A., Lulich, J.P., Kruger, J.M., Sanderson, S.L., Koehler, L.A., Ulrich, L.K. (1999). Canine urate urolithiasis: etiopathogenesis, diagnosis, and management. Veterinary Clinics of North America: Small Animal Practice 29, 161-191.

Berent, A., Tobias, K. (2009). Portosystemic vascular anomalies. Veterinary Clinics of North America: Small Animal Practice 39, 513-541.

Berent, A., Weisse, C. (2007). Portosystemic shunts and portal venous hypoplasia. Standards of Care: Emergency and Critical Care Medicine 9, 1-11.

Caporali, E.H.G., Phillips, H., Underwood, L., Selmic, L.E. (2015). Risk factors for urolithiasis in dogs with congenital extrahepatic portosystemic shunts: 95 cases (19992013). Journal of the American Veterinary Medical Association 246, 530-536.

D’Anjou, M.A., Penninck, D., Cornejo, L., Pibarot, P. (2004). Ultrasonographic diagnosis of portosystemic shunting in dogs and cats. Veterinary Radiology \& Ultrasound 45, 424-437.

Dimski, D.S. (1994). Ammonia metabolism and the urea cycle: function and clinical implications. Journal of Veterinary Medicine 8, 73-78.

Evans, H.E., de Lahunta, A. (2013). The urogenital system. In: Evans, H.E. and de Lahunta, A. (editors). Miller's anatomy of the dog. Fourth edition, Elsevier Saunders, Missouri, p. 316-405.

Howe, L.M., Boothe, H.W. (2002). Diagnosing and treating portosystemic shunts in dogs and cats. Veterinary Medicine 97, 448-459.

Hurn, S.D., Edwards, G.A. (2003). Perioperative outcomes after three different single extrahepatic portosystemic shunt attenuation techniques in dogs: partial ligation, complete ligation and ameroid constrictor placement. Australian Veterinary Journal 81, 666-670.

Kraun, M.B., Nelson, L.L., Hauptman, J.G., Nelson, N.C. (2014). Analysis of the relationship of extrahepatic portosystemic shunt morphology with clinical variables in dogs: 53 cases (2009-2012). Journal of the American Veterinary Medical Association 245, 540-549.

Lamb, C.R. (1998). Ultrasonography of portosystemic shunts in dogs and cats. Veterinary Clinics of North America: Small Animal Practice 28, 725-753.

Lamb, C.R., Daniel, G.B. (2002). Diagnostic imaging of dogs with suspected portosystemic shunting. Compendium on Continuing Education of the Practicing Veterinarian - North American Edition 24, 626-635.

Markowitz, J., Rappaport, A., Scott A.C. (1949). The function of the hepatic artery in the dog. The American Journal of Digestive Diseases 16, 344-348.

Mehl, M.L., Kyles, A.E., Hardie, E.M., Kass, P.H., Adin, C.A., Flynn, A.K., De Cock, H.E., Gregory, C.R. (2005). Evaluation of ameroid ring constrictors for treatment for single extrahepatic portosystemic shunt in dogs: $168 \mathrm{ca}-$ ses (1995-2001). Journal of the American Veterinary Medical Association 226, 2020-2030.

Nelson, N.C., Nelson, L.L. (2011). Anatomy of extrahepatic portosystemic shunts in dogs as determined by computed tomography angiography. Veterinary Radiology \& Ultrasound 52, 498-506.

Osborne, C.A., Kruger, J.M., Johnston, G.R., Polzin, D.J. (1986). Dissolution of canine ammonium urate uroliths. Veterinary Clinics of North America: Small Animal Practice 16, 375-388.

Paepe, D., Haers, H., Vermote, K., Saunders, J., Risselada, M., Daminet, S. (2007). Portosystemic shunts in dogs and cats: definition, epidemiology and clinical signs of congenital portosystemic shunts. Vlaams Diergeneeskundig Tijdschrift 76, 234-240.

Tisdall, P.L.C., Rothwell, T.L.W., Hunt, G.B., Malik, R. (1996). Glomerulopathy in dogs with congenital portosystemic shunts. Australian Veterinary Journal 73, 5254.

van den Ingh, T.S., Rothuizen, J., Meyer, H.P. (1995). Circulatory disorders of the liver in dogs and cats. Veterinary Quarterly 17, 70-76.

Winkler, J.T., Bohling, M.W., Tillson, D.M., Wright, J.C., Ballagas, A.J. (2003). Portosystemic shunts: diagnosis, prognosis, and treatment of 64 cases (1993-2001). Journal of the American Animal Hospital Association 39, 169-185.

Worley, D.R., Holt, D.E. (2008). Clinical outcome of congenital extrahepatic portosystemic shunt attenuation in dogs five years and older: 17 cases (1992-2005). Journal of the American Veterinary Medical Association 232, 722-727. 